\title{
Structure-activity relationship analysis on the basis of matched molecular pairs
}

Anne Mai Wassermann

From 9th German Conference on Chemoinformatics

Fulda, Germany. 10-12 November 2013

Matched molecular pairs (MMPs), i.e., pairs of compounds that are related to each other by a specific molecular transformation, have become an integral tool of drug discovery [1,2]. Generally spoken, matched molecular pair analysis (MMPA) aims at the extraction of all MMPs from a set of compounds and their association with calculated or measured property changes. Using public bioactivity data, we have used MMPs as a consistent reference framework to identify sets of chemical replacements that either have the propensity to induce large-magnitude potency changes or tend to retain compound potency across diverse targets [3,4]. Furthermore, we have extended the concept of MMPs to matched molecular series, i.e., analog series with different molecular core structures but corresponding substitution patterns $[5,6]$. The identification of series with alternative core structures but similar SAR trends is highly relevant for lead optimization where SAR information from one series that has been explored historically is ideally used to guide compound design efforts for a new chemotype [6].
6. Wassermann AM, Bajorath J: A data mining method to facilitate SAR transfer. J Chem Inf Model 2011, 51:1857-1866.

\section{doi:10.1186/1758-2946-6-S1-014}

Cite this article as: Wassermann: Structure-activity relationship analysis on the basis of matched molecular pairs. Journal of Cheminformatics 2014 6(Suppl 1):014.

\section{References}

1. Griffen E, Leach AG, Robb GR, Warner DJ: Matched molecular pairs as a medicinal chemistry tool. J Med Chem 2011, 54:7739-7750.

2. Dossetter AG, Griffen EJ, Leach AG: Matched molecular pair analysis in drug discovery. Drug Discov Today 2013, 18:724-731.

3. Wassermann AM, Bajorath J: Chemical substitutions that introduce activity cliffs across different compound classes and biological targets. J Chem Inf Model 2010, 50:1248-1256.

4. Wassermann AM, Bajorath J: Large-scale exploration of bioisosteric replacements on the basis of matched molecular pairs. Future Med Chem 2011, 3:425-436.

5. Wawer M, Bajorath J: Local structural changes, global data views: graphical substructure-activity relationship trailing. J Med Chem 2011, 54:2944-2951.

Correspondence: anne_mai.wassermann@novartis.com

Novartis Institutes for Biomedical Research, Cambridge, MA, 02139, USA

\section{Publish with ChemistryCentral and every scientist can read your work free of charge \\ "Open access provides opportunities to our colleagues in other parts of the globe, by allowing anyone to view the content free of charge." \\ W. Jeffery Hurst, The Hershey Company. \\ - available free of charge to the entire scientific community \\ - peer reviewed and published immediately upon acceptance \\ - cited in PubMed and archived on PubMed Central \\ - yours - you keep the copyright \\ Submit your manuscript here: \\ http://www.chemistrycentral.com/manuscript/

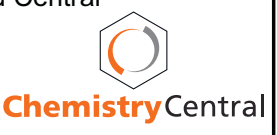

